Journal of Applied Pharmaceutical Science Vol. 5 (06), pp. 120-126, June, 2015

Available online at http://www.japsonline.com

DOI: $10.7324 /$ JAPS.2015.50620

ISSN 2231-3354 (cc) BY-NC-SA

\title{
Evaluation as antioxidant agents of 1,2,4-triazolederivatives: effects of essential functional groups
}

\author{
Ahmet Cetin, Ibrahim Halil Geçibesler \\ Department of Chemistry, Faculty of Science and Art, Bingol University, 12000, Turkey.
}

\begin{tabular}{|c|c|}
\hline ARTICLE INFO & ABSTRACT \\
\hline Article history: & \multirow{9}{*}{$\begin{array}{l}\text { A series of } 1,2,4-\text { triazole derivative compounds substituted with groups of phenol and pyridine were synthesized } \\
\text { in high yields and screened against several antioxidant activity parameters such as DPPH, ABTS, metal } \\
\text { chelating, reducing power and the total antioxidant activity. The compounds showed better than expected } \\
\text { antioxidant activity between the studied biological activity parameters. Among these, compound G }(2-(5- \\
\text { mercapto- } 4 \mathrm{H}-1,2,4-\text { triazol- } 3 \text {-yl)phenol) had a high total antioxidant activity potential with value of } 232.12 \pm 6.89 \\
\text { mmol/ml. Also showed fairly good ABTS cation radical and DPPH radical scavenging activity with values of } \\
\mathrm{IC}_{50}=4.59 \pm 4.19 \text { and } \mathrm{IC}_{50}=7.12 \pm 2.32 \mu \mathrm{g} / \mathrm{mL} \text { respectively. Further, the antioxidant potential of heterocyclic } \\
\text { compounds that } 1,2,4-\text { triazole derivatives containing different functional groups were compared with various } \\
\text { tests performed and has been shown to increase the activity of electron donating groups. Therefore, the present } \\
\text { study demonstrates that phenol and pyridine substituted } 1,2,4 \text {-triazole compounds would be a better prospective } \\
\text { in the development of antioxidant agent. }\end{array}$} \\
\hline $\operatorname{Re}$ & \\
\hline & \\
\hline & \\
\hline Available & \\
\hline Key we & \\
\hline 1,2,4-triazole, antioxidant & \\
\hline activity, 2 -(5-mercapto-4H- & \\
\hline & \\
\hline
\end{tabular}

\section{INTRODUCTION}

In recent times there is increasing interest in the nitrogen-containing such as triazole heterocyclic compounds as utilized in medicinal chemistry. Currently the drugs used for treatment such as Ribavirin (antiviral agent), Rizatriptan (antimigraine agent), Alprazolam (anxiolytic agent), Fluconazole and Itraconazole (antifungal agents) are the best examples for potent molecules possessing triazole nucleus. (Knabe et al., 1983; Lopes et al., 2004). The 1,2,4-Triazoles is another heterocyclic ring having value as human therapeutic agents. Biological activity studies related with 1,2,4-triazole ring system promotes it as an interesting class of heterocyclic compounds with a broad spectrum of pharmacological activities which include antifungal (Karabasanagouda et al., 2007), anti-inflammatory, analgesic (Chawla et al., 2012), antitumor (Ibrahim, 2009), anthelmintic (El-Khawass et al., 1989), antibacterial (Holla et al., 1996), antihypertensive, antidepressant, anticonvulsant and antiviral (Kritsanida et al., 2002). Free radicals are chemical species containing one or more unpaired electrons, most of them being unstable and capable of abstracting electrons from other molecules.

\footnotetext{
* Corresponding Author

Email: ibrahimgecibesler@gmail.com
}

The predominant reactive oxygen species generated by cell metabolism or by exogenous factors include hydrogen peroxide $\left(\mathrm{H}_{2} \mathrm{O}_{2}\right)$, the hydroxyl radical $(\mathrm{HO})$, the superoxide anion radical $\left(\mathrm{O}_{2} \bullet^{-}\right)$. These free radicals have essential roles in cell signaling, apoptosis and gene expression. On the other hand, excessive free radical attack can damage DNA, proteins and lipids, resulting in diseases like cancer, neurological degeneration and arthritis, as well as the process of aging (Halliwell and Gutteridge, 1990; Halliwell et al., 1992). Therefore, considerable speculation has been directed towards the identification of antioxidants for use in preventive medicine. The radical-mediated oxidation of DNA is related to many diseases (Jomova et al., 2010). In addition, the radical-scavenging capacities of antioxidants can be estimated by reacting with 2,2'-azinobis(3-ethylbenzothiazoline-6-sulfonate) cationic radical (ABTS) ( $\operatorname{Re}$ et al., 1999)and 2,2-diphenyl-1picrylhydrazyl radical (DPPH)(Foti et al., 2011). During the inflammatory processes many reactive species are produced, among them reactive oxygen species (ROS) such as, superoxide radical $\left(\mathrm{O}_{2} \bullet^{-}\right)$, hydrogen peroxide $\left(\mathrm{H}_{2} \mathrm{O}_{2}\right)$, hypochlorous acid $(\mathrm{HOCl})$, singlet oxygen $\left({ }^{1} \mathrm{O}_{2}\right)$ and peroxyl radical (ROO•), as well as reactive nitrogen species $(\mathrm{RNS})$, like nitric oxide $(\bullet \mathrm{NO})$ and peroxynitrite anion $\left(\mathrm{ONOO}^{-}\right)$. Indeed, ROS and RNS are also produced by the endothelial cells, Kupffer cells, neutrophils and 
macrophages as mechanism of defense against foreign infectious pathogens (Vapaatalo, 1986; Halliwell et al., 1988; MouithysMickalad et al., 2000; Nikolic and Breemen, 2001).

To date, the prevention of oxidative stress related diseases has been tentatively achieved by the development of antioxidant compounds that are able to scavenge ROS and RNS, and thus avoid radical-induced oxidation damage. When a validated scaffold has been identified, the study of structure reactivity relationship (SAR) may provide useful information for the understanding of its mode of action and to the improvement of the antioxidant activity of future generated compounds.

In the present study, due to a wide range of applications to find their possible antioxidant activity, some 1,2,4-triazole derivatives A-M, functionalized with phenolic, thiol, 2-hydroxy benzene, and pyridine groups were evaluated by using different antioxidant methodologies such as:2,2'-azinobis(3ethylbenzothiazoline-6-sulfonate) cationic radical (ABTS) scavenging, reducing power, 1,1-diphenyl-2-picryl-hydrazyl (DPPH) free radical scavenging, total antioxidant and metal chelating activities. The search and evaluation of 1,2,4-triazole compounds and their derivatives with a specific pharmacological activity is a demanding task in the drug discovery process. In this context, the study of structure reactivity relationship (SAR) is a valuable tool for the planning of potential novel drugs and, in a later stage, for the development of novel treatments.

\section{MATERIALS AND METHODS}

\section{Materials}

The Ferrous chloride, $\alpha$-tocopherol (Vit E), 1,1-diphenyl2-picryl-hydrazyl (DPPH), 3-(2-pyridyl)-5,6-bis(phenylsulfonic acid)-1,2,4-triazine (ferrozine), butylatedhydroxyanisole (BHA), ethylene-diaminetetraacetic acid (EDTA), trichloroacetic acid (TCA) Diammonium salt of 2,2'-azinobis(3-ethylbenzothiazoline6-sulfonate) (ABTS salt), were purchased from Merck, SigmaAldrich and Fluka. Other agents and solvents were of analytical grade and used without further purification directly.

\section{Synthesis of Compounds}

The required compounds were prepared as reported in literature (Genc et al., 2004;Dincer et al; 2005; Cansiz et al., 2012). Thus, 5-Pyridin-4-yl-4H-1,2,4-triazole-3-thiol(A)4-Ethyl-5pyridin-4-yl-4H-1,2,4-triazole-3-thiol(B)4-Phenyl-5-pyridin-4-yl4H-1,2,4-triazole-3-thiol (C)4 - (4-Methylphenyl)-5-pyridin-4-yl4H-1,2,4-triazole-3-thiol (D)4-Benzyl-5-pyridin-4-yl-4H-1,2,4triazole-3-thiol (E)4-Allyl-5-pyridin-4-yl-4H-1,2,4-triazole-3-thiol (F)2 - (5-mercapto-4H-1,2,4-triazol-3-yl) phenol (G)2 - (4-Ethyl5-mercapto-4H-1,2,4-triazol-3-yl) phenol (H)2 - (5-Mercapto-4phenyl-4H-1,2,4-triazol-3-yl) phenol (I)2 - [5-Mercapto-4-(4methylphenyl)-4H-1,2,4-triazol-3-yl] phenol (K)2 - (4-Benzyl-5mercapto-4H-1,2,4-triazol-3-yl) phenol (L)2 - (4-Allyl-5mercapto-4H-1,2,4-triazol-3-yl) phenol(M)were prepared: structures are listed in Table 1.

\section{DPPH free radical-scavenging activity}

The samples were tested with DPPH free radical according to the method previously defined by Zovko Koncic et al., (2010)with some modifications. Shortly, $0.5 \mathrm{ml}$ of synthesized compounds and synthetic antioxidant compound (BHA) prepared at different concentrations $(12,5-400 \mu \mathrm{g} / \mathrm{ml})$ were taken into test tubes and stirred with $2.5 \mathrm{ml}$ of $2 \mathrm{mM}$ DPPH solution. The mixture was stirred thoroughly and incubated for $30 \mathrm{~min}$ in dark laboratory conditions. The absorbance at a wavelength of $517 \mathrm{~nm}$ was measured by UV spectrophotometry. To determine DPPH free radical scavenging activity (FRSA) was used in the following equation.

$$
\operatorname{FRSA}(\%)=\left[\left(\mathrm{A}_{0}-\mathrm{A}_{1}\right) / \mathrm{A}_{0}\right] \times 100
$$

$\mathrm{A}_{0}$ is the absorbance values without specimen and $\mathrm{A}_{1}$ the absorbance in the presence of specimen. As opposed to increasing concentration of specimens decline of absorbance is an indication that destroyed DPPH radical. Antioxidant activity results are expressed as $\mathrm{IC}_{50}$ value $(\mu \mathrm{g}$ extract $/ \mathrm{mL}$ ) that reduces by half the effective concentration of DPPH radicals and was calculated by interpolation from linear regression analysis.

\section{Ferrous chelating capacity}

The ferrous chelating capacity of samples and the reference compound (EDTA) was conducted following the method used by Decker and Welch (1990) with slight modifications. $2 \mathrm{ml}$ of extract, sub-fractions and reference compound (EDTA) of concentration labeling between 25 and $250 \mu \mathrm{g} / \mathrm{mL}$ were added to $50 \mu \mathrm{l}$ of $2 \mathrm{mM} \mathrm{FeCl}_{2}$ and well mixed. The reaction mixture was incubated in laboratory conditions. The reaction occurred by the addition of $100 \mu 15 \mathrm{mM}$ ferrozine. After $10 \mathrm{~min}$ of incubation period, the absorbance of the solution was measured at $562 \mathrm{~nm}$ using a UV-visible spectrophotometer. For the ferrous-chelating activity, $\mathrm{IC}_{50}$ values were calculated using the equation as described above was used for DPPH free radical scavenging activity.

\section{Assay of Reducing Power}

The reducing power was determined according to the method of Oyaizu (1986) with slight modifications various concentrations of triazole derivatives $(2.5 \mathrm{ml})$ were mixed with 2.5 $\mathrm{ml}$ of $200 \mathrm{mM}$ sodium phosphate buffer (pH 6.6) and $2.5 \mathrm{ml}$ of $1 \%$ potassium ferricyanide.

The mixture was incubated at $50{ }^{\circ} \mathrm{C}$ for $20 \mathrm{~min}$. After 2.5 $\mathrm{ml}$ of $10 \%$ trichloroacetic acid (w/v) were added, the mixture was centrifuged at $1000 \mathrm{rpm}$ for $8 \mathrm{~min}$. The upper layer $(5 \mathrm{ml})$ was mixed with $5 \mathrm{ml}$ of deionized water and $1 \mathrm{ml}$ of $0.1 \%$ of ferric chloride, and the absorbance was measured spectrophotometrically at $700 \mathrm{~nm}$. The assays were carried out in triplicate and the results expressed as mean values \pm standard deviations. BHA, BHT and $\alpha$-tocopherol were used as standards. It was indicated that high absorbance of the sample was good reducing power in the reaction conditions. 


\section{Evaluation of total antioxidant capacity by phosphomolybdenum method}

The total antioxidant capacity of samples was evaluated by the method of Prieto, Pineda, and Aguilar(1999) with slight modifications. The antioxidant capacity of the extracts was measured spectrophotometrically using a phosphomolybdenum method, based on the reduction of $\mathrm{Mo}(\mathrm{VI})$ to $\mathrm{Mo}(\mathrm{V})$ by the sample analyte and the subsequent formation of specific green phosphate/Mo(V) compounds. An aliquot of $0.1 \mathrm{~mL}$ of sample solution $(100 \mu \mathrm{g} / \mathrm{mL})$ was combined with $1 \mathrm{~mL}$ of reagent solution (0.6 M sulfuric acid, $28 \mathrm{mM}$ sodium phosphate and $4 \mathrm{mM}$ ammonium molybdate). The tubes were capped and incubated in a boiling water bath at $95{ }^{\circ} \mathrm{C}$ for $90 \mathrm{~min}$. After the samples had cooled to room temperature, the absorbance of the aqueous solution of each was measured at $695 \mathrm{~nm}$ against blank. A typical blank solution contained $1 \mathrm{~mL}$ of reagent solution and the appropriate volume of the same solvent used for the sample and it was incubated under same conditions as rest of the sample. Stock solutions of $\alpha$-tocopherol were prepared in methanol. The total antioxidant activity was expressed as equivalents of $\alpha$-tocopherol (mmol $\alpha$-tocopherol $/ \mathrm{ml}$ ).

\section{ABTScation radical scavenging activity}

To determine the antioxidant activity of compounds, ABTS cation radical-scavenging activity was employed in this study with slight modifications (Re et al., 1999). The ABTS cation radical cation was generated by mixing ABTS stock solution (7 $\mathrm{mM}$ in water) with $2.45 \mathrm{mM}$ potassium persulfate. This mixture was kept at ambient temperature for $24 \mathrm{~h}$ until the reaction was complete and the absorbance was stable. Briefly, $1.9 \mathrm{ml}$ of an ABTS cation radical was added to $0.1 \mathrm{ml}$ of different concentrations of standard (trolox) or samples. After $10 \mathrm{~min}$, an absorbance was read at $734 \mathrm{~nm}$, and distilled water was used as a blank (each measured in triplicate). The $\mathrm{IC}_{50}$ is the concentration of an antioxidant that is required to quench $50 \%$ of the initial ABTS cation radicals under the experimental conditions given. Trolox, a well-known antioxidant, was used as a positive control.

\section{RESULTS AND DISCUSSION}

\section{DPPH radical scavenging activity}

The DPPH radical scavenging activity 1,2,4-triazole derivatives containing phenol groups (H-M) have shown comparable antioxidant potential with the BHA. whereas the compounds (A-F) showed a moderate DPPH radical scavenging activity. In compounds (A-F) pyridine rings are present at triazole ring while in compounds $(\mathrm{G}-\mathrm{M})$ the phenol ring are present at triazole ring which different contributed in the radical scavenging ability. It is clear from the results that the antioxidant potential of compounds is associated with the substituents on mentioned 1,2,4triazole rings. The inhibition percentage of compounds and Vit-E at different concentrations are given in Fig.1A.Compound G showed highest DPPH scavenging activity with percent inhibition of $93.751 \pm 0.47$ at concentration of $100 \mu \mathrm{g} / \mathrm{ml}$, when compared with the other compounds. This increased activity may be due to existence of the $-\mathrm{SH},-\mathrm{C}_{6} \mathrm{H}_{5} \mathrm{OH}$, and $-\mathrm{NH}$ groups. The presence of phenolic group was inadequate for antioxidant activity.

DPPH radical scavenging is a widely used method to evaluate antioxidant activities in a relatively short time compared with other methods. DPPH radical scavenging activities of synthesized compounds (A-M) were tested using ethanolic solution of the stable free radical DPPH. The freshly prepared DPPH solution exhibits a deep purple color generally convert them to a colorless/ bleached product when an antioxidant is present in the medium. Thus, antioxidant compounds can quench DPPH free radical by providing hydrogen atoms or by electron donation resulting in absorbance at $517 \mathrm{~nm}$ and the more rapidly the absorbance decreases, the more potent the antioxidant activity of the compounds. The 1,2,4-triazole derivatives compounds was found to be significantly active against DPPH radical. On DPPH assay, $\mathrm{IC}_{50}$ values were obtained for compounds and $\mathrm{BHA}$, so that a lower value of $\mathrm{IC}_{50}$ indicated a higher antioxidant activity and vice versa. Table 1 shows the statistical analysis of DPPH radical scavenging activity and value of $\mathrm{IC}_{50}$ obtained from antioxidant activity of compounds and BHA (as a reference compound). The compound $\mathrm{G}$ with an $\mathrm{IC}_{50}$ value $7.12 \pm 2.32 \mu \mathrm{g} / \mathrm{mL}$ was found to be more active than the standard antioxidant BHA.

Table. 1:Chemical structure of 1,2,4-triazole derivative compounds.
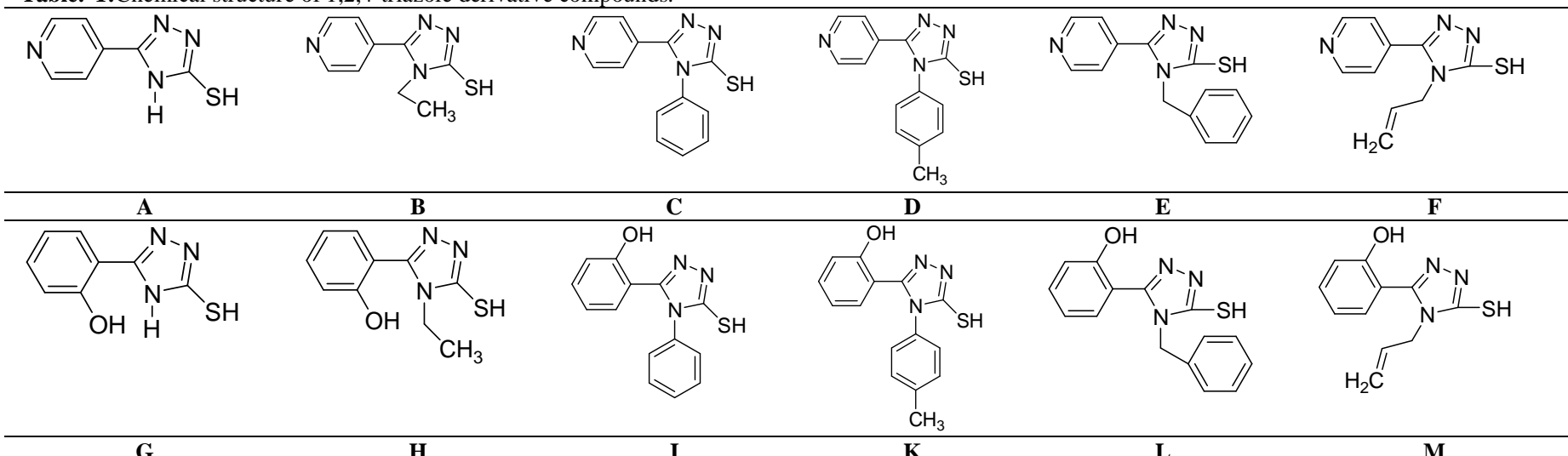

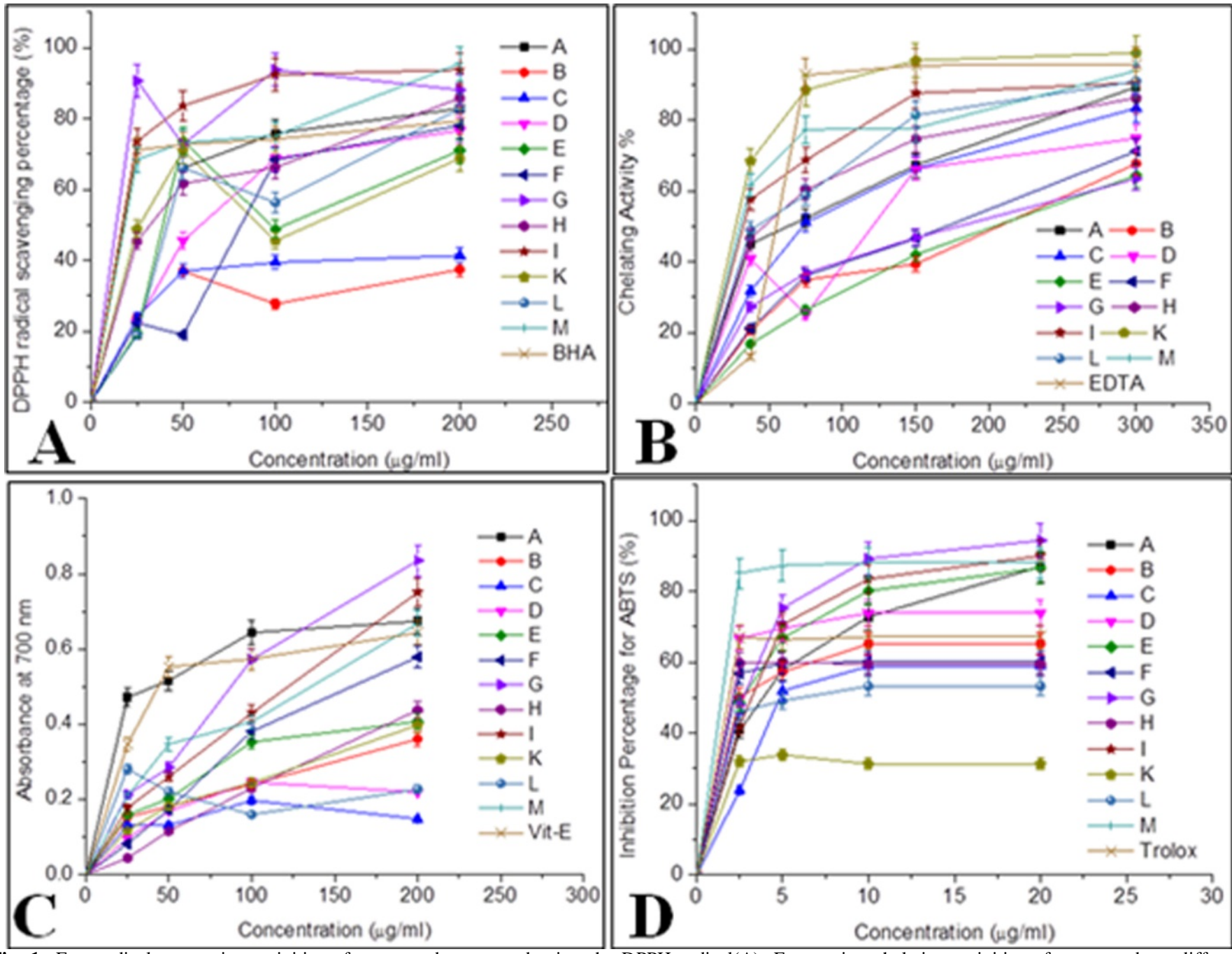

Fig. 1: Free radical-scavenging activities of compounds measured using the DPPH radical(A), Ferrous ion chelating activities of compounds at differen concentrations (B), Reducing power of compounds at different concentrations by spectrophotometric detection of the $\mathrm{Fe} 3+-\mathrm{Fe} 2+$ transformation (C), High absorbance at $700 \mathrm{~nm}$ indicates high reducing power. Concentration-response curves for inhibition of the absorbance of ABTS cation radical at $734 \mathrm{~nm}$ for compounds (D). Results are means \pm SD $(n=3)$.

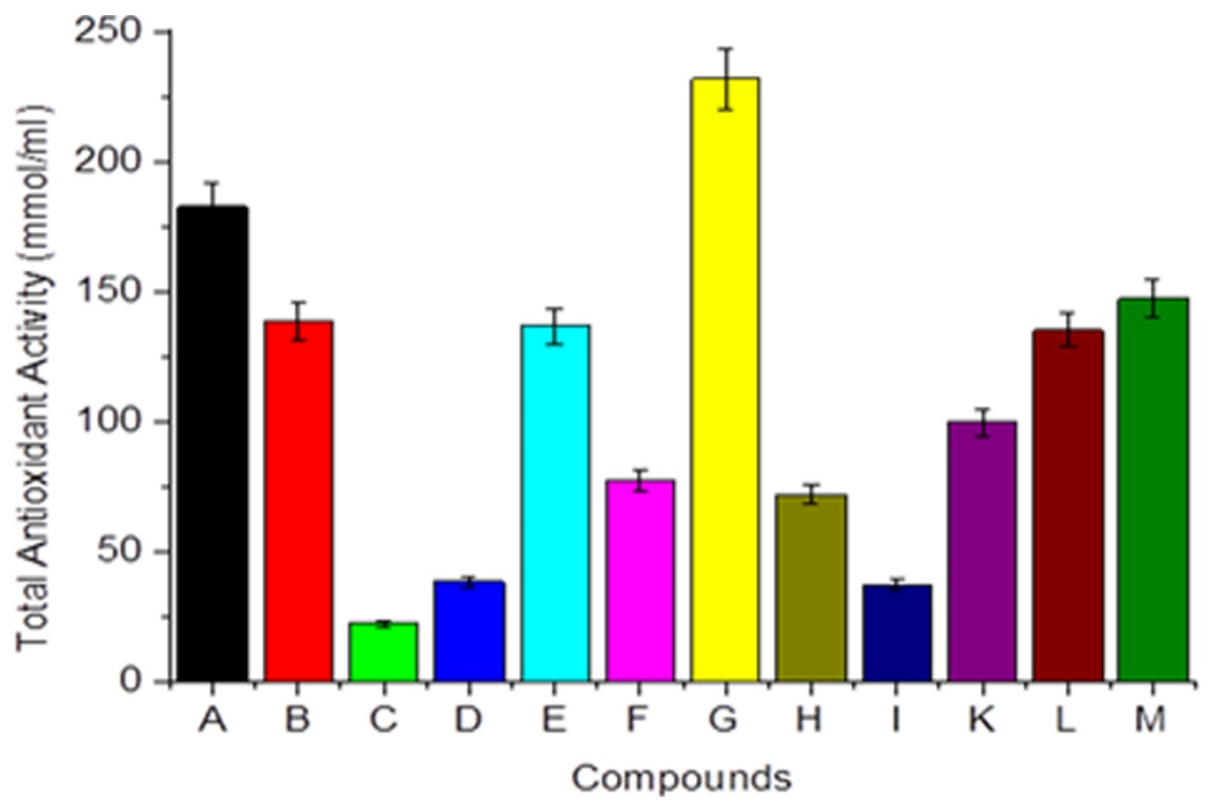

Fig. 2 Total antioxidant activity of compounds measured by phosphomolybdenum reduction assay. Each value represents means $\pm \operatorname{SD}(n=3)$. 


\section{Ferrous ion chelating activity}

Ferrous ion chelating activities of the compounds and EDTA are shown in Table $1 \mathrm{IC}_{50}$ for $\mathrm{Fe}^{2+}$ chelating ability were60.16 $\pm 2.65, \quad 66.76 \pm 1.14$ and $79.29 \pm 2.33 \mu \mathrm{g} / \mathrm{ml}$ for compounds G, M and L, respectively. Furthermore, the percentage inhibition of compounds obtained from Fig.1Breveal that the metal chelating effects of the compounds $\mathrm{D}$ were concentrationdependent the other compounds were not. Thus the compounds D demonstrate a marked capacity for iron chelating, suggesting that their action as peroxidation protectors may be related to their iron chelating capacity. However, the ferrous ion chelating activities of compounds were lower than the EDTA $\left(\mathrm{IC}_{50}=28.48 \pm 0.65 \mu \mathrm{g} / \mathrm{ml}\right) \mathrm{It}$ was reported that the compounds with structures containing two or more of the functional groups, such as -OH. -SH.-COOH. $-\mathrm{PO}_{3} \mathrm{H}_{2}$. $\mathrm{C}=\mathrm{O}$.- $\mathrm{NR}_{2} \cdot-\mathrm{S}-.-\mathrm{O}-$ in a favourable structure-function configuration should have chelation activity (Lindsay, 1996; Yuan et al., 2005; Gulcin, 2006). In this respect, compound G may chelate the ferrous ions with hydroxyl and thiol groups.

Transition metals have a pivotal role in the generation of oxygen free radicals in living organism. The production of these radicals may lead to lipid peroxidation, protein modification and DNA damage. Chelating agents may inactivate these metal ions and potentially inhibit the metal-dependent processes (Finefrock $e t$ al., 2003). Compounds with metal chelating activity have ability to convert metal ions into insoluble metal complexes or generate steric hindrance, which can prevent the interactions between metals. In the presence of chelating agents the complex formation is disrupted with the result that the red colour of the complex is decreased.

Measurement of colour reduction therefore allows estimation of the chelating activity of the coexisting chelators (Yamaguchi et al., 2000). The ferrous state of iron accelerates lipid oxidation by breaking down the hydrogen and lipid peroxides to reactive free radicals. The ferric iron $\left(\mathrm{Fe}^{3+}\right)$ is the relatively biologically inactive form of iron. $\mathrm{Fe}^{3+}$ but ion produces radicals from peroxides, even though the rate is tenfold less than that of $\mathrm{Fe}^{2+}$ ion, which is the most powerful pro-oxidant among the various types of metal ions (Calıs et al., 1993). Chelating agents may not activate metal ions and potentially inhibit the metaldependent processes (Finefrock et al., 2003). Free iron is known to have low solubility and a chelated iron complex has greater solubility in solution, which can be contributed solely by the ligand. Furthermore, the compound-iron complex may also be active, since it can participate in iron-catalyzed reactions.

\section{Reducing power capacity}

The capacity of reducing power of 1,2,4-triazole derivatives was almost comparable with the synthetic antioxidant, Vitamine E (Vit-E). The reducing power of test compounds increases with increase in concentration. Compounds $\mathrm{C}-\mathrm{D}$ and $\mathrm{L}$ exhibited very low absorption, whereas compounds A, I, M and G were found to have higher absorption at a high concentration of $200 \mu \mathrm{g} / \mathrm{ml}$. The actively mentioned 1,2,4-triazole derivatives could reduce the most $\mathrm{Fe}^{3+}$ ions, which had a higher reductive activity than the reference standard of Vit-E. Reducing power of the compounds mostly depended on the groups where the compounds were substituted. The presence of pyridine, thiol and phenol functions in the 1,2,4-triazole compounds may play an important role to act as a better electron donor which may enhance reducing power ability of active compounds. The reducing power of the investigated the 1,2,4-triazole derivatives differed according to containing phenol and pyridine groups. This may be due to the substitution of electron-releasing groups at 1,2,4-triazole compounds, which may be helping for stabilization of the free radical form after donating electron and thus to leading maximum reducing ability compared to other less active compounds.

The reducing capacity of a compound may serve as a significant indicator of its potential antioxidant activity. Reducing power is a measure of reductive ability of antioxidants and is evaluated by the transformation of $\mathrm{Fe}^{3+}$ to $\mathrm{Fe}^{2+}$ in the presence of compounds. The reducing ability of a compound generally depends on the presence of reductants (Duh et al., 1999), which have been exhibited antioxidative potential by breaking the free radical chain, donating a hydrogen atom (Gordon, 1990). The presence of reductants (i.e. antioxidants) causes the reduction of the $\mathrm{Fe}^{3+} /$ ferricyanide complex to the ferrous form. Therefore, the $\mathrm{Fe}^{2+}$ can be monitored by measuring the formation of Perl's Prussian blue at $700 \mathrm{~nm}$. Fig.1C show the dose-response curves for the reducing power of synthesized compounds (A-M) examined as a function of their concentration. The data shows that the reducing power of compounds increased in a dose dependent manner.

\section{ABTS cation radical-scavenging activity}

As shown in Fig.1Din the 1,2,4-triazole derivatives decrease the concentrations of ABTS cation radical at different concentrations demonstrating that 1,2,4-triazole ring and its substituted functional groups such as $-\mathrm{OH}-\mathrm{SH}$ and $-\mathrm{NH}$ can quench ABTS cation radical efficiently. The ABTS radicalscavenging activity of the compounds (A-M) revealed that amongst all the tested compounds. Among the triazole compounds compound $\mathrm{G}$ was found to be the best, followed by compounds $\mathrm{A}$ and $\mathrm{M}$. Compounds $\mathrm{B}$ and $\mathrm{D}$ exhibited minimum scavenging activity against ABTS cation radical. Compounds $\mathrm{H}$ and $\mathrm{F}$ exhibited similar activity (Table1). The ABTS cation radical scavenging activity of compound $\mathrm{G}$ was pretty good than that of trolox.

Free radical-scavenging property is the basic feature for a compound to be an antioxidant. For this, which are simple, fast and reliable ABTS cation radical scavenging activity used to test the ability of 1,2,4-triazole derivatives. This was assessed by taking hydrogen atom, under in vitro conditions and then adding increasing concentrations of test compounds. The absorbance was taken at $734 \mathrm{~nm}$. It is well accepted that the ABTS cation radical scavenging by antioxidants is attributable to their hydrogen donating ability. 


\section{The total antioxidant activity}

The total antioxidant activity (equivalent to $\alpha$-tocopherol) values in $\mathrm{mmol} / \mathrm{ml}$ are presented in Table 1 varied in synthesized compounds and ranged from $22.64 \pm 7.18$ to $232.12 \pm 6.89$ $\mathrm{mmol} / \mathrm{mL}$. The highest total antioxidant activity have been detected in compound $\mathrm{G}$ with the value $232.12 \pm 6.89 \mathrm{mmol} / \mathrm{mL}$ and the lowest in compound $\mathbf{C}$ with the value $22.64 \pm 7.18 \mathrm{mmol} / \mathrm{mL}$. Compounds B, E and L (139.04 $\pm 2.13,137.08 \pm 2.92$ and $135.56 \pm 1.73 \mathrm{mmol} / \mathrm{mL}$, respectively), Compounds $\mathrm{F}$ and $\mathrm{H}$ $(77.64 \pm 0.32$ and $72.20 \pm 1.32 \mathrm{mmol} / \mathrm{mL})$ and Compounds $\mathrm{A}$ and $\mathrm{D}(37.64 \pm 3.76$ and $38.84 \pm 3.43 \mathrm{mmol} / \mathrm{mL})$ demonstrated the similar total antioxidant activities among themselves(see Fig.2).

The total antioxidant activity (TAA) of the synthesized compounds was evaluated by the phosphomolybdenum method. The methods already available for the evaluation of TAA due to its simplicity and the cheap reagents it uses. The assay is based on the reduction of $\mathrm{Mo}(\mathrm{VI})$ to $\mathrm{Mo}(\mathrm{V})$ by the test compounds and subsequent formation of a green phosphate/Mo(V) complex at acid $\mathrm{pH}$. The results of the total antioxidant activity (TAA) are expressed as mmol $\alpha$-tocopherol per ml. The higher the TAA value, the more effective the antioxidant activity.

Table 2: Antioxidant activity of compounds in the performed assays.

\begin{tabular}{|c|c|c|c|c|}
\hline \multirow{2}{*}{ Compounds } & \multicolumn{3}{|c|}{$\mathrm{IC}_{50}(\mu \mathrm{g} / \mathrm{mL})^{\mathrm{a}}$} & \multirow{2}{*}{$\begin{array}{c}\mathrm{TAA}^{\mathrm{e}} \\
(\mathrm{mmol} / \mathrm{ml})\end{array}$} \\
\hline & $\mathbf{A B T S}^{\mathbf{b}}$ & DPPH $^{c}$ & $\mathrm{CA}^{\mathrm{d}}$ & \\
\hline $\mathbf{A}$ & $7.06 \pm 5.65$ & $78.27 \pm 1.27$ & $109.34 \pm 0.61$ & $182.88 \pm 4.43$ \\
\hline B & $34.62 \pm 6.70$ & $265.48 \pm 2.63$ & $199.56 \pm 1.12$ & $139.04 \pm 2.13$ \\
\hline $\mathbf{C}$ & $11.95 \pm 1.23$ & $209.35 \pm 4.73$ & $195.79 \pm 2.08$ & $22.64 \pm 7.18$ \\
\hline D & $75.54 \pm 4.18$ & $95.39 \pm 1.59$ & $151.18 \pm 0.71$ & $38.84 \pm 3.43$ \\
\hline $\mathbf{E}$ & $5.66 \pm 1.87$ & $100.48 \pm 1.13$ & $211.68 \pm 1.34$ & $137.08 \pm 2.92$ \\
\hline $\mathbf{F}$ & $8.89 \pm 0.73$ & $106.52 \pm 4.34$ & $181.82 \pm 7.18$ & $77.64 \pm 0.32$ \\
\hline G & $4,59 \pm 4.19$ & $7.12 \pm 2.32$ & $60.16 \pm 2.65$ & $232.12 \pm 6.89$ \\
\hline $\mathbf{H}$ & $8.78 \pm 3.23$ & $69.78 \pm 3.51$ & $97.18 \pm 2.12$ & $72.20 \pm 1.32$ \\
\hline I & $5.61 \pm 1.69$ & $18.46 \pm 2.18$ & $81.43 \pm 2.48$ & $37.64 \pm 3.76$ \\
\hline $\mathbf{K}$ & $8.57 \pm 0.77$ & $89.46 \pm 2.15$ & $126.83 \pm 5.47$ & $100.00 \pm 4.13$ \\
\hline $\mathbf{L}$ & $12.93 \pm 4.21$ & $89.10 \pm 0.44$ & $79.29 \pm 2.33$ & $135.56 \pm 1.73$ \\
\hline M & $4.67 \pm 2.73$ & $38.48 \pm 2.99$ & $66.76 \pm 1.14$ & $147.64 \pm 3.14$ \\
\hline Trolox & $5.76 \pm 0.54$ & ND & ND & ND \\
\hline BHA & ND & $38.04 \pm 0.98$ & ND & ND \\
\hline EDTA & ND & ND & $28.48 \pm 0.65$ & ND \\
\hline
\end{tabular}

ND: Not detected

${ }^{\mathrm{a}}$ Concentration that shows $50 \%$ activity.

b2,2'-azinobis(3-ethylbenzothiazoline-6-sulfonate) cationic radical scavenging activity.

${ }^{\mathrm{c}}$ 1,1-diphenyl-2-picryl-hydrazyl free radical scavenging activity.

${ }^{\mathrm{d}}$ Chelating activity.

${ }^{\mathrm{e}}$ Total antioxidant activity (equivalent to $\alpha$-tocopherol)

\section{CONCLUSION}

The some heterocyclic compounds are being recognised as a source of numerous bioactive compounds. Many of them were shown to possess antioxidant properties and inhibit radicals by the effect of electron donating groups or supplying hydrogen atom. The 1,2,4-triazole derivative compounds were shown to have significant antioxidant properties as measured by various antioxidant assays. These heterocyclic compounds have the potential of being easily may be synthesis with high efficiency and for use in forward pharmacological studies. Moreover, the synthesis procedure of compounds offers several advantages including good yields, operational simplicity and cleaner reaction which makes it a useful and attractive process for the synthesis of these compounds. In this study relationship with substituted functional groups to 1,2,4-triazole rings and antioxidant potentials were found for the tested compounds relies mainly on their electron-rich moieties, which hold high resonance stability.

\section{ACKNOWLEDGEMENTS}

The authors thank for financial support the Scientific and Technological Research Council of Turkey (TUBITTAK; 111T560) and the Scientific Research Project Department of Bingol University (BÜBAP; 2010-07)

\section{REFERENCES}

Calıs, I., Zor, M.,Basaran, A.A.,Wright, A.D., Sticher, Karsoside, O. and Scropolioside, D. Two New Iridoid Glycosides from Scrophularia ilwensis. J. Nat. Prod., 1993; 56:606-9.

Cansiz, A. Cetin, A. Orek, C.Karatepe, M.Sarac, K.Kus., A.Koparir, P. 6-Phenyl-3-(4-pyridyl)-1,2,4-triazolo- [3,4-b] [1,3,4] thiadiazole: synthesis, experimental,theoretical characterization and biological activitiesSpectrochimica Acta Part A-Molecular And Biomolecular Spectroscopy, 2012; 97:606-15.

Chawla, G. Kumar, U. Bawa, S. Kumar, J.Syntheses and evaluation of anti-inflammatory, analgesic and ulcerogenic activities of 1,3,4-oxadiazole and 1,2,4-triazolo[3,4-b]-1,3,4-thiadiazole derivatives. J Enzyme Inhib. Med. Chem., 2012; 27:658-65.

Decker, E.A. and Welch, B. Role of ferritin as a lipid oxidation catalyst in muscle food.J. Agric. Food. Chem., 1990; 38:674-7.

Dincer, M. Ozdemir, N. Cetin, A. Cansı, A.Buyukgungor, O. 6-phenyl-3-(4-pyridyl)-1,2,4-triazolo[3,4-b][1,3,4]thiadiazole.Acta

Crystallographica Section C-Crystal Structure Communications, 2005; 61:0665-7.

Duh, P.D.Tu, Y.Y. Yen, G.C. Antioxidant activity of water extracts of HarngJyur(Chrisanthemunmorifolium Ramat). Lebensm-Wiss Technol., 1999; 32: 269-77.

El-Khawass,S.M.Khalil, M.A. Hazzaa, A.A. Bassiouny, H.A. Loutfy, N.F. Synthesis of some 1,2,4-triazolo [3,4-b] [1,3,4] thiadiazoles as potential anthelmintics.Farmaco, 1989; 44: 703.

Finefrock, A.E. Bush, A.I. Doraiswamy, P.M. Current status of metals as therapeutic targets in Alzheimer's disease.J. Am. Geriatr. Soc., 2003; 51:1143-8.

Foti, M. C. Daquino, C. DiLabio, G. A. Ingold, K. U. Kinetics of the oxidation of quercetin by 2,2-diphenyl-1-picrylhydrazyl (dpph•). Org. Lett., 2011; 13: 4826-9.

Genc, S. Dege, N. Cetin, A. Cansiz, A. Sekerci, M. Dincer, M. 3-(2-Hydroxyphenyl)-4-phenyl-1H-1,2,4-triazole-5(4H)-thione. Acta Crystallographica Section E-Structure Reports Online, 2004; 60: O1580-2.

Gordon, M.F. 1990. The mechanism of antioxidant action in vitro InFood antioxidants BJF Hudson EdElsevier Applied Science London pp. 1.

Gülçin, I. Antioxidantactivity of caffeic acid (3,4dihydroxycinnamic acid). Toxicol, 2006; 217;213-20.

Halliwell, B. and Gutteridge, J. M. C. Role of free radicals and catalytic metal ions in human disease: an overview.Methods Enzymol, 1990; 186: 1-85.

Halliwell, B.Cross, C.E. and Gutteridge J.M.C. Free radicals, antioxidants, and human disease: where are we now?.J Lab. Clin. Med., 1992; 119: 598-620

Halliwell, B. Hoult, J. R. Blake, D. R. Oxidants, inflammation, and anti-inflammatory drugs. The FASEB J., 1988; 2:2867-73.

Holla, B.S.Shivananda, M.K. Akberali, P.M. Baliga, S. Safeer, S. Studies On Arylfuran Derivatives .6. Synthesis, Characterization and Antibacterial Activities of Some 6-(5-Aryl-2-Furyl)-1,2,4-Triazolo [3,4- 
B]-1,3,4-Thiadiazoles and -2-Furyl)-1,2,4-Triazolo[3,4-B]-1,3,4Thiadiazoles.Farmaco, 1996; 51:785-92.

Ibrahim, D.A. Synthesis and biological evaluation of 3,6disubstituted $[1,2,4]$ triazolo[3,4-b][1,3,4]thiadiazole derivatives as a novel class of potential anti-tumor agents. Eur. J. Med. Chem., 2009; 44: 277681 .

Jomova, K. Vondrakova, D.Lawson, M.Valko, M. Metals, oxidative stress and neurodegenerative disorders.Mol. Cell.Biochem., 2010; 345:91-104.

Karabasanagouda, T.Adhikari, A.V. Shetty, N.S. Synthesis and antimicrobial activities of some novel 1,2,4-triazolo[3,4-b]-1,3,4thiadiazoles and 1,2,4-triazolo[3,4-b]-1,3,4-thiadiazines carrying thioalkyl and sulphonyl phenoxy moieties.Eur. J. Med. Chem., 2007; 42:521-9.

Knabe, J.Buch, H.P. and Schmitt, W. Derivatives of barbituric acid cytostatic and CNS activities of chiral barbiturate mannich-bases. Arch. Pharm. Chem. Life. Sci., 1983; 316: 1051-3.

Kritsanida, M. Mouroutsou, A. Marakos, P. Pouli, N. Papakonstantinou-Garoufalias, S. Pannecouque, C. Witvrouw, M. De Clercq, E. Synthesis and antiviral activity evaluation of some new 6substituted 3-(1-adamantyl)-1,2,4-triazolo[3,4-b][1,3,4]thiadiazoles. Farmaco, 2002; 57:253-7.

Lindsay, R.C. 1996. Food additives In: Food Chemistry O.R. Fennema Ed: Marcel Dekker Inc. New York. pp 778-80.

Lopes, F. Capela, R. Goncaves, J. O. Horton, P.N. Hursthouse, M.B. Iley, J. Casimiro, C.M.Bom, J. and Moreire, R. Amidomethylation of amodiaquine: antimalarial N-Mannich base derivatives.Tetrahedron Lett., 2004; 45: 7663-6.

Mouithys-Mickalad, A. M. L. Zheng, S. X. Deby-Dupont, G.P Deby, C. M. Lamy, M. Reginster, J. Y. Y. Henrotin Y. E. In vitro study of the antioxidant properties of non-steroidal anti-inflammatory drugs by chemiluminescence and electron spin resonance (ESR). Free Radic. Res., 2000; 33: 607-21.
Nikolic, D. van Breemen, R.B. DNA oxidation induced by cyclooxygenase-2.Chem. Res. Toxicol, 2001;14:351-4.

Oyaizu, M. Antioxidantactivities of products of browningreactionpreparedfromglucosamine. Studies on products of the browning reaction. Jpn. J. Nutr., 1986; 44: 307-15.

Prieto, P. Pineda, M.\& Aguilar, M. Spectrophotometric quantitation of antioxidant capacity through the formation of a phosphomolybdenum complex: specific application to the determination of vitamin E. Analytical Biochemistry, 1999; 269:337-41.

Re, R. Pellegrini, N.Proteggente, A. Pannala, A.Yang, M.RiceEvans, C. Antioxidant activity applying an improved ABTS radical cation decolorization assay. Free Radic. Biol. Med., 1999; 26:1231-7.

Vapaatalo, H. Free radicals and anti-inflammatory drugs.Med. Biol., 1986; 64:1-7.

Yamaguchi, F. Ariga, T. Yoshimira, Y.Nakazawa, H. Antioxidative and Anti-Glycation Activity of Garcinol from Garcinia indica Fruit Rind. Journal of Agricultural and Food Chemistry, 2000; 48: 180-85.

Yuan, Y.V. Bone, D.E.Carrington, M. F. Antioxidant activity of dulse (Palmaria palmata) extract evaluated in vitro.Food Chem., 2005; 91:485-94.

Zovko Koncic, D. Kremer, K. Karlovic, K. and Kosalec, I. Evaluation of antioxidant activities and phenolic content of Berberis vulgaris L. and Berberis croatica Horvat.Food Chem. Toxicol, 2010;48:2176-80

\section{How to cite this article:}

Ahmet Cetin and Ibrahim Halil Geçibesler. Evaluation as antioxidant agents of 1,2,4-triazole derivatives: essential functional group effects. J App Pharm Sci, 2015; 5 (06): 120-126. 